Case Report

\title{
Adjuvant Radiotherapy for Synchronous Bilateral Testicular Seminoma: A Case Report and a Review of the Pertinent Literature
}

\author{
Daniel A. Jones, ${ }^{1}$ Elizabeth C. Ester, ${ }^{1}$ David Leavitt, ${ }^{2}$ Robert Sweet, ${ }^{2}$ Badrinath Konety, ${ }^{2}$ \\ Gautam Jha, ${ }^{3}$ and L. Chinsoo Cho ${ }^{1}$ \\ ${ }^{1}$ Department of Radiation Oncology, University of Minnesota Medical Center, Minneapolis, MN 55455, USA \\ ${ }^{2}$ Department of Urology, University of Minnesota Medical Center, Minneapolis, MN 55455, USA \\ ${ }^{3}$ Department of Medicine, Division of Hematology, Oncology, Bone Marrow Transplantation, Masonic Cancer Center, \\ University of Minnesota Medical Center, Minneapolis, MN 55455, USA \\ Correspondence should be addressed to Daniel A. Jones; adamjones172001@yahoo.com
}

Received 8 March 2013; Accepted 23 April 2013

Academic Editors: S.-S. Chen, G. L. Gravina, and F. Ramezanzadeh

Copyright (C) 2013 Daniel A. Jones et al. This is an open access article distributed under the Creative Commons Attribution License, which permits unrestricted use, distribution, and reproduction in any medium, provided the original work is properly cited.

\begin{abstract}
Few cases of synchronous bilateral stage I seminomas have been reported in the world literature. We present a case of bilateral synchronous testicular seminoma, the current literature on the management of stage I seminoma, and the implications for radiotherapy. A forty-year-old man presented with synchronous bilateral classical seminomas, both stage IA. After undergoing bilateral inguinal orchiectomy, he received adjuvant external beam radiotherapy, with a standard paraaortic field. After 18 months of followup, he remains well, without evidence of recurrence. Bilateral germ cell tumors (BGCTs) are reported consistently at a low rate. Bilateral radical inguinal orchiectomy is standard of care, yet some groups have proposed an organ preservation approach. Of the reported cases of bilateral stage I synchronous GCT, with concordant seminoma histology, most of them were treated with bilateral orchiectomy and adjuvant radiotherapy. Although morbidity associated with radiotherapy directed at the abdomen is not negligible, adjuvant paraaortic radiotherapy remains safe and well-tolerated treatment regime. Bilateral synchronous stage I seminoma of the testes is rare. Organ preservation remains investigational. Chemotherapy is probably a reasonable option. We propose that patients with bilateral stage I synchronous GCT, with concordant seminoma histology, should be managed with bilateral orchiectomy, followed by paraaortic radiotherapy.
\end{abstract}

\section{Introduction}

According to a publication by the American Cancer Society, there was an estimated 8590 new cases of testicular cancer in the United States in 2012, accounting for only 360 deaths [1]. Testicular germ cell tumors (GCTs) make up a majority of these cases. Men diagnosed with testicular GCT are at higher risk for development of a second cancer in the contralateral testes, and the incidence of bilateral testicular germ cell tumor (BGCT) ranges from $1 \%$ to $4 \%$ in selected series, as highlighted in Table 1 [2-12].

Furthermore, the incidence of synchronous BCGT is much less common, accounting for less than $0.5 \%$ of all diagnoses of testicular cancer. Of the synchronous presentations of BGCT, it is quite rare to see a presentation of stage I synchronous concordant seminoma in both testes, as indicated in Table 2 [2-4, 6, 7, 9-12]. Most of these patients have been managed initially with bilateral orchiectomy, followed by adjuvant radiation therapy. Field sizes, dose, and fractionation regiments generally were not reported. Nearly all patients, in this small cohort, at the time of publication had no evidence of disease NED (Table 2). By our review of the literature, there have been no reported cases of observation after bilateral orchiectomy of synchronous seminomatous BGCT. As the paradigm of management for stage I seminoma is shifting to a more conservative approach, for 
TABLE 1: Incidence of bilateral germ cell tumor in select series.

\begin{tabular}{lcc}
\hline Author (reference) & $\begin{array}{c}\text { Total number } \\
\text { testicular germ cell } \\
\text { tumors }\end{array}$ & $\begin{array}{c}\text { Bilateral germ cell } \\
\text { tumor (BGCT) (\%) }\end{array}$ \\
\hline Patel et al. [2] & 795 & $19(2.3)$ \\
Wanderås et al. [3] & 2225 & $68(3.0)$ \\
Coogan et al. [4] & 2088 & $21(1.0)$ \\
Sonneveld et al. [5] & 445 & $16(3.6)$ \\
Ondrus et al. [6] & 960 & $27(2.8)$ \\
Che et al. [7] & 2431 & $24(1.0)$ \\
Ohyama et al. [8] & 274 & $9(3.2)$ \\
Géczi et al. [9] & 2386 & $72(3.0)$ \\
Holzbeierlein et al. [10] & 3984 & $58(1.5)$ \\
Theodore et al. [11] & 2383 & $45(1.9)$ \\
Hentrich et al. [12] & 1180 & $47(4.0)$ \\
\hline
\end{tabular}

bilateral testicular germ cell tumors, adjuvant radiotherapy or chemotherapy probably remains the best option.

\section{Case Presentation}

The patient is a forty-one-year-old man with an unremarkable medical history presented with a two-month history of scrotal swelling and discomfort. He denied a history of maldescent, and there was no family history of testicular cancer. Physical exam was pertinent for an enlarged, nontender left testicle. An ultrasound revealed well-circumscribed hypoechoic, heterogeneous lesions in both testicles (Figure 1). The left testicular mass measured $3.0 \times 2.6 \times 4.3 \mathrm{~cm}$, while the mass in the right testicle measured $2.1 \times 3.1 \times 0.5 \mathrm{~cm}$. Doppler was suggestive of normal blood flow. Pertinent labs included (AFP) alpha fetoprotein $6.2 \mu \mathrm{g} / \mathrm{L}$, (beta HCG) beta human chorionic gonadotropin < $3 \mathrm{IU} / \mathrm{L}$, (LDH) lactase dehydrogenase levels $572 \mathrm{U} / \mathrm{L}$, and serum testosterone $375 \mathrm{ng} / \mathrm{dL}$, and all prognostic markers are within normal limits. CT of the chest, abdomen, and pelvis was negative for evidence of metastatic disease or lymphadenopathy.

$\mathrm{He}$ underwent bilateral inguinal orchiectomy. Final pathology (Figure 2) revealed classical seminoma in both specimens. Both right and left tumors exhibited invasion of the rete testis. There was possible angiolymphatic space invasion noted within the left testicular mass. There was no tumor extension through the tunica albuginea, epididymis, or spermatic cord. Surgical margins were free. Both tumors were pathologically staged IA.

The patient did not have concerns regarding fertility and declined to consider an organ preserving approach. Our patient was uncomfortable with surveillance as an option. He declined medical oncology referral for discussion about systemic therapy and was therefore treated with external beam radiotherapy. He received $2550 \mathrm{cGy}$ in 17 fractions at 150 cGy per fraction via $6 \mathrm{MV} / 18 \mathrm{MV}$ photons with $\mathrm{AP} / \mathrm{PA}$ fields. Field borders (Figure 3 ) included superior border at T10/11 interspace, inferior border at L5/S1 interspace, and lateral borders of vertebral transverse processes (field width approximately $10 \mathrm{~cm}$ ). The patient did not have a history of previous pelvic surgery, and only the paraaortic lymph nodes were targeted. He tolerated treatment well, experiencing grade I nausea (as per Common Terminology Criteria for Adverse Events, version 3.0). He is currently disease-free, 18 months from completion of radiation therapy. His serum testosterone levels fell to $248 \mathrm{ng} / \mathrm{dL}$ after treatment, and he uses testosterone gel for hormone replacement.

\section{Discussion}

Risk factors for development of testicular cancer have been reported by Dieckmann et al. and are described by a relative risk, odds ratio and include undescended testis (3.5-17.1,), contralateral GCT (24.8-27.6,), familial testis cancer (2.1-12.3,), and gonadal dysgenesis (up to $25 \%$ cumulative risk.) Other risk factors which have less evidence include dizygotic twin ship (1.5-2.4), infertility (1.6-10), and testicular atrophy (2.7-12.7) [13]. Incidence of testicular intratubular neoplasia (TIN) in the contralateral testes at the time of diagnosis of GCT has been reported at a rate of 6.6\% [14]. Some believe that biopsy of the contralateral tumor at the time of orchiectomy is appropriate, while others do not recommend this as common practice [15]. Since the incidence of metachronous GCT is less than the incidence of TIN, one can conclude that TIN does not necessarily lead to cancer. BGCTs are reported to occur in a younger population compared to testicular cancer as a whole, and by one report, at a median age of 29 years versus median age of 34 years for solitary testicular GCT [14]. Although once debated in the literature, BGCTs are likely not increasing in incidence, and the apparent increased number of metachronous tumors is probably due to increased life expectancy of the general population [10]. BGCTs are reported consistently at a very low rate, previously mentioned, in Table 1 , and although they occur usually within five years, they may occur much later, and therefore long term follow-up is recommended. In the largest U.S. series of BGCT, the author reports the diagnosis of the second lesion appearing at a time period greater than ten years after the original diagnosis in $23 \%$ of the cohort [10]. The incidence of metachronous tumors is two to ten times higher than synchronous tumors. Synchronous tumors are as likely to harbor divergent histology, as in Table 2. Seminoma is believed to be more commonly involved in the case of BGCTs as opposed to nonseminoma [16]. Synchronous tumors were once thought to represent more advanced staged disease, but this has not been demonstrated in the multiple series reviewed in this paper.

The synchronous presentation of bilateral stage I testicular seminomatous germ cell tumors presents a unique discussion regarding the role of and need for adjuvant therapy. Adjuvant radiation therapy after inguinal orchiectomy has resulted in excellent local control. After five years, recurrence, free survival and cause-specific survival are consistently reported at $95 \%$ and $98-99 \%$, respectively $[17,18]$. Doses reductions from $30 \mathrm{~Gy}$ to $20 \mathrm{~Gy}$ were achieved without compromising outcomes [19]. Furthermore, treatment to the paraaortic field was found to be equivalent to the dogleg, in 
TABLE 2: Select series, incidence of BGCT and synchronous stage I seminomas, therapy, and outcomes.

\begin{tabular}{|c|c|c|c|c|c|c|c|c|c|}
\hline Author & Years studied & BGCT & S-BGCT & CS-BGCT & $\begin{array}{c}\text { CS-BGCT } \\
\text { Stage I }\end{array}$ & $\begin{array}{l}\text { Adjuvant } \\
\text { radiation }\end{array}$ & FS & Dose (Gy) & Outcome \\
\hline Patel et al. [2] & $\begin{array}{c}1935-44 \\
1977-86\end{array}$ & 19 & 4 & 2 & 2 & $2 / 2$ & - & - & $\begin{array}{c}{ }^{* * *} \text { Died in } \\
<2 \text { yrs }\end{array}$ \\
\hline Wanderås et al. [3] & $1953-1990$ & 68 & 8 & 7 & $\begin{array}{l}7 / 8 \text { all } \\
\text { stages }\end{array}$ & $\begin{array}{c}\text { Likely All } \\
\text { got RT }\end{array}$ & $\begin{array}{l}{ }^{* *} \text { Inver- } \\
\text { ted Y }\end{array}$ & $30-40$ & - \\
\hline Coogan et al. [4] & Unknown & 21 & 5 & 3 & 2 & $2 / 2$ & - & - & NED \\
\hline Ondrus et al. [6] & 1977-2001 & 27 & 3 & 1 & 1 & $1 / 1$ & - & - & NED \\
\hline Che et al. [7] & 1978-1999 & 24 & 4 & 3 & 3 & $3 / 3$ & - & - & NED \\
\hline Géczi et al. [9] & 1988-1998 & 72 & 19 & 13 & ${ }^{*} 8$ & $5 / 19$ & - & - & $\begin{array}{c}5 \mathrm{yr} \text { OS } \\
84 \%\end{array}$ \\
\hline Holzbeierlein et al. [10] & $1950-2001$ & 58 & 10 & 3 & $2 / 3$ & $2 / 2$ & - & - & - \\
\hline Theodore et al. [11] & 1997-2002 & 45 & 14 & 9 & 1 & - & - & - & - \\
\hline Hentrich et al. [12] & $1979-2003$ & 47 & 9 & 4 & 2 & $1 / 2$ & - & - & NED \\
\hline
\end{tabular}

BGCT: bilateral germ cell tumor; S-BGCT: synchronous bilateral germ cell tumor; CS-BGCT: classic seminoma, synchronous bilateral germ cell tumor; FS: field size; ${ }^{*}$ did not differentiate those who were CS-BGCT and stage I; ${ }^{* *}$ pre 1980 , included groins in anterior field for higher risk patients; ${ }^{* * *}$ both who died in $<2$ yrs were treated in 1935-1944 era; - : not reported.

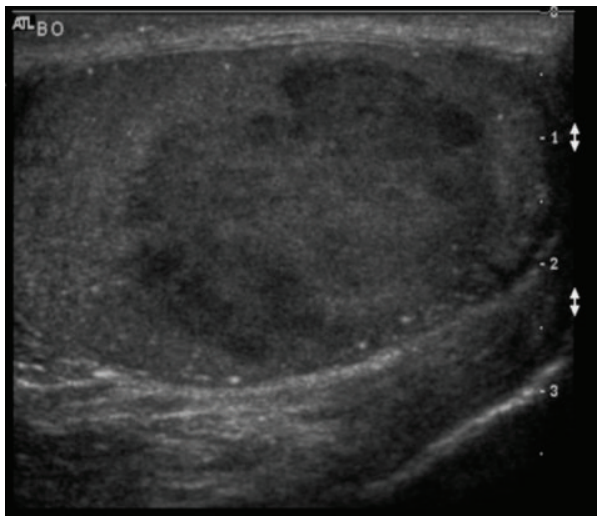

(a)

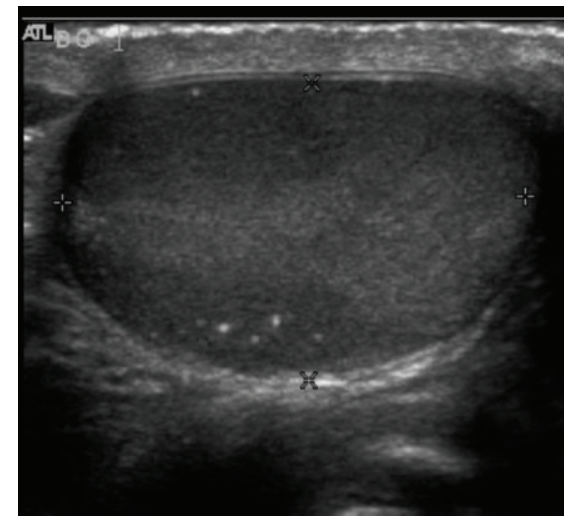

(b)

FIgURE 1: Scrotal ultrasound. (a) (R), (b) (L).

a pelvis not previously disrupted with surgery [20]. Current radiation therapy standards include doses of 20-25 Gy at 1.5-2.0 Gy/day, treated with AP/PA fields, directed to the retroperitoneal lymph nodes, typically T10/T11 through L5 S1, $8-10 \mathrm{~cm}$ wide, and with consideration for accounting for left renal vein/IVC confluence (Figure 3 ). While radiotherapy has been excellent at preventing recurrence, chemotherapy with carboplatin is also very effective, possibly with a more favorable toxicity profile.

Platinum-based chemotherapy regiments are effective at preventing recurrence of seminoma and are generally well tolerated. In a randomized study, carboplatin (AUC $7 \times 1$ cycle) was found not to be inferior to radiotherapy with regards to 5-year RFS (94.7\% versus $96.0 \%$.) In addition, at a median followup of 6.5 years, the carboplatin arm experienced a reduced number of contralateral GCT compared to the radiotherapy arm, HR $0.22(P=0.03)$ [21]. Chemotherapy may confer an advantage to radiotherapy in that less patients experience a metachronous testicular tumor. Others have suggested that chemotherapy is not effective at preventing the incidence of a metachronous GCT [12]. For patients with synchronous germ cell tumors who undergo bilateral orchiectomy, at least short term, this advantage of chemotherapy no longer would exist.

If radiation therapy is used in the initial management of a patient, this would probably limit the ability to reirradiate in the event of onset of contralateral metachronous GCT years later, due to approaching the tolerance of small bowel. Regardless of how an initial GCT was managed, a populationbased US study revealed that incidence of a second testicular GCT did not decrease survival [15]. Therefore, the increased incidence of metachronous GCT after radiotherapy compared systemic therapy should not be a major factor determining a treatment regimen.

Furthermore, surveillance, now accepted as category I evidence in the USA, is employed routinely after orchiectomy for stage I seminoma [22]. In a US cohort, managed with observation, at five years, men experienced $89.2 \%$ RFS, $98.8 \%$ OS, and 100\% CSS [23]. Aparicio et al. described a riskadapted approach, placing patient with stage I seminomas, 


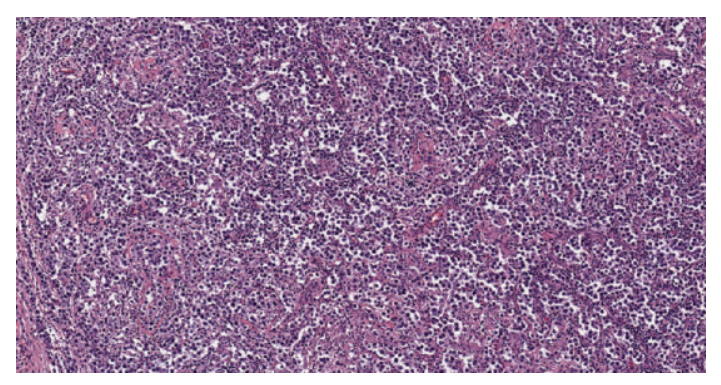

(a)

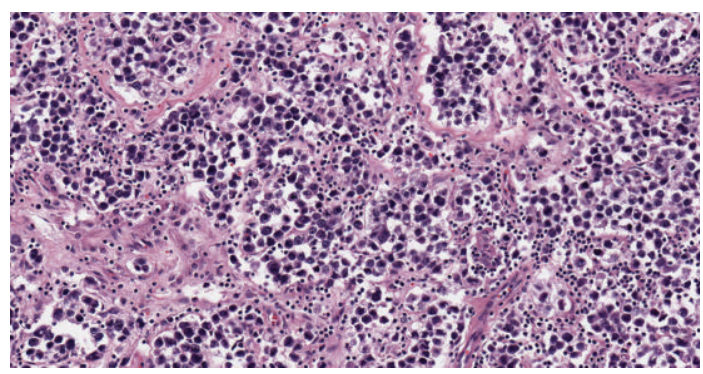

(c)

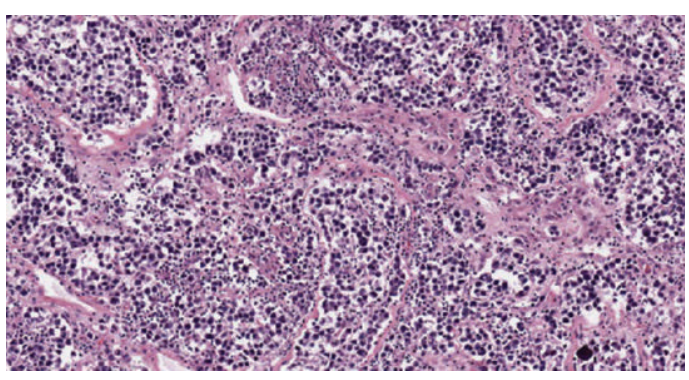

(b)

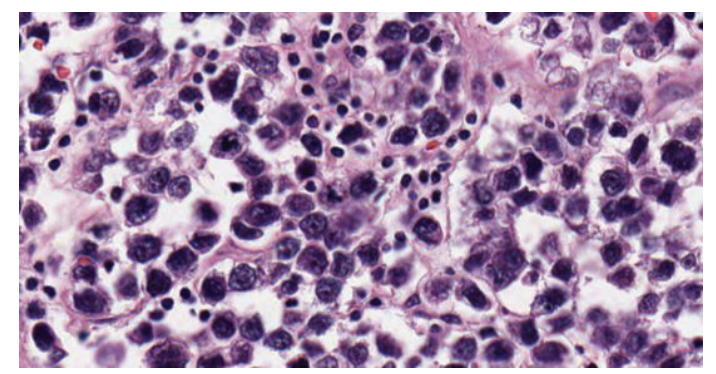

(d)

Figure 2: Surgical pathology. (a) Right testicle low power 4x, (b) left testicle low-power 4x, (c) 10x, and (d) 20x.

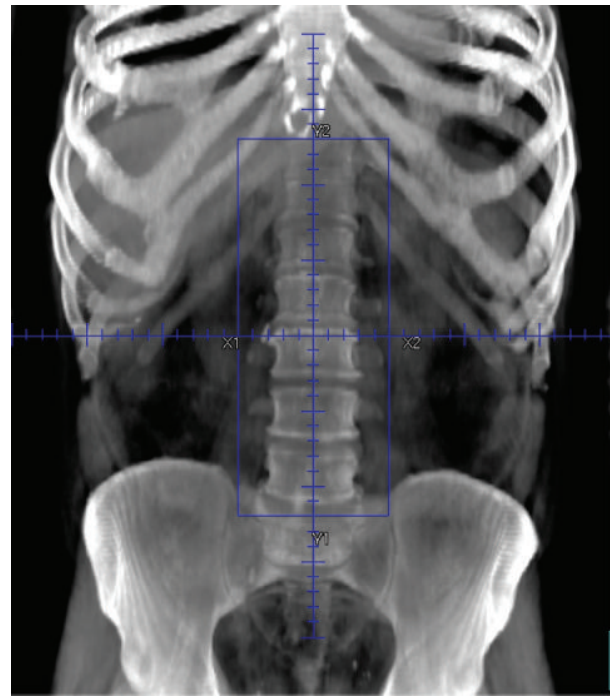

Figure 3: Paraaortic field (DCR).

$<4 \mathrm{~cm}$, without rete testis invasion on a surveillance protocol. They reported a 3 -year DFS of $88.1 \%$, all of which were recurred in the retroperitoneum and were salvaged with Etoposide and Cisplatin chemotherapy. Three-year overall survival was $100 \%$ [24]. We are not aware of any literature that supports surveillance for this rare tumor.

Bilateral radical inguinal orchiectomy is considered the standard of care for patients with bilateral testicular germ cell tumors. Given the resultant infertility and need for indefinite androgen replacement therapy, some groups have proposed an organ preservation approach in selected patients. However, this remains controversial and goes against oncologic principles [25-28]. Potential candidates for organ preservation include those patients with organ confined bilateral tumors or tumors within a solitary testicle [27]. Tumors larger than $2 \mathrm{~cm}$ are rarely amenable to partial orchiectomy because total tumor excision often leaves insufficient remaining viable testicular parenchyma. Tomita et al. detailed a particular strategy for organ preservation in eight patients with bilateral testicular tumors. In these patients, radical inguinal orchiectomy was performed for the larger testis tumor. If pathology confirmed seminoma, then patients had their contralateral testis spared and received chemotherapy (three cycles of Bleomycin, Etoposide, and Cisplatin). Local control was maintained for the cohort, although one patient died of distant disease [29]. When utilizing testis preservation approaches, close and frequent postoperative surveillance with scrotal ultrasound has been suggested [25]. In general, testis-sparing strategies for testicular germ cell tumors are controversial but may be considered in highly selected patients. In our case, the patient declined preservation as an option.

Of the reported cases of bilateral stage I synchronous GCT, with concordant seminoma histology (Table 2), most of them were treated with bilateral orchiectomy and adjuvant radiotherapy. The Geczi series did not delineate patients with bilateral stage I, patients with concordant seminoma, but patients of the 19 synchronous BGCT; 5 were treated with adjuvant radiation [9]. Of the 2 cases of synchronous stage I seminomatous BGCT in the Hentrich series, one was treated with radiotherapy and the other with chemotherapy [12]. Otherwise, radiation therapy was used in all the others noted series for this particularly rare scenario. Dose, fractionation, and field size records were not generally reported $[2-4,6,7$, 9-12]. 
For bilateral stage I synchronous testicular germ cell tumors, the current standard of care is to perform bilateral radical inguinal orchiectomy, and then to consider adjuvant therapy. In the current case, adjuvant radiotherapy was recommended due to bilateral rete testis invasion and possible angiolymphatic space invasion of the larger lesion. Perhaps the presence of bilateral germ cell tumors is a negative prognostic factor, yet this may be difficult to demonstrate due to the small number of cases. Although morbidity associated with low-dose radiotherapy directed at the abdomen is not negligible, the adjuvant paraaortic radiotherapy remains safe and well-tolerated treatment regime.

\section{Conclusions}

For patients with stage I seminoma, surveillance, radiotherapy, or chemotherapy is reasonable options following orchiectomy. These patients have a good prognosis, regardless of treatment choice. Bilateral synchronous stage I seminoma of the testes is rare, with few cases reported in the literature. Our patient was treated with radiotherapy, like a majority of these patients have been managed historically. Bilateral orchiectomy is standard of care. Organ preservation remains investigational but may be considered for selected patients. Similar prognostic factors should be considered for adjuvant therapy for bilateral testicular germ cell tumors when compared to unilateral germ cell tumors. Surveillance has not been described in patients with bilateral germ cell tumors after orchiectomy. Chemotherapy is probably a reasonable option. Due to the lack of evidence, we propose that patients with bilateral stage I synchronous GCT, with concordant classical seminoma histology, should be managed with bilateral orchiectomy, followed by paraaortic radiotherapy.

\section{Acknowledgment}

This paper is presented in poster format, in American College of Radiation Oncology 2013, San Antonio, February 14-16, 2013.

\section{References}

[1] American Cancer Society, Cancer Facts \& Figures 2012, American Cancer Society, Atlanta, Ga, USA, 2012.

[2] S. R. Patel, R. L. Richardson, and L. Kvols, "Synchronous and metachronous bilateral testicular tumors. Mayo clinic experience," Cancer, vol. 65, no. 1, pp. 1-4, 1990.

[3] E. H. Wanderås, S. D. Fosså, and S. Tretli, "Risk of a second germ cell cancer after treatment of a primary germ cell cancer in 2201 Norwegian male patients," European Journal of Cancer Part A, vol. 33, no. 2, pp. 244-252, 1997.

[4] C. L. Coogan, R. S. Foster, G. R. Simmons, P. G. Tognoni, B. J. Roth, and J. P. Donohue, "Bilateral testicular tumors: management and outcome in 21 patients," Cancer, vol. 83, no. 3, pp. 547-552, 1998.

[5] D. J. A. Sonneveld, H. Schraffordt Koops, D. T. Sleijfer, and H. J. Hoekstra, "Bilateral testicular germ cell tumours in patients with initial stage I disease: prevalence and prognosis-a single centre's 30 years' experience," European Journal of Cancer, vol. 34, no. 9, pp. 1363-1367, 1998.

[6] D. Ondrus, M. Hornnak, and J. Matoska, "Bilateral testicular germ-cell tumors-a single centre long-term experience," International Urology and Nephrology, vol. 33, no. 3, pp. 521-524, 2001.

[7] M. Che, P. Tamboli, J. Y. Ro et al., "Bilateral testicular germ cell tumors: twenty-year experience at M. D. Anderson Cancer Center," Cancer, vol. 95, no. 6, pp. 1228-1233, 2002.

[8] C. Ohyama, A. Kyan, M. Satoh et al., "Bilateral testicular tumors: a report of nine cases with long-term follow-up," International Journal of Urology, vol. 9, no. 3, pp. 173-177, 2002.

[9] L. Géczi, F. Gomez, M. Bak, and I. Bodrogi, "The incidence, prognosis, clinical and histological characteristics, treatment, and outcome of patients with bilateral germ cell testicular cancer in Hungary," Journal of Cancer Research and Clinical Oncology, vol. 129, no. 5, pp. 309-315, 2003.

[10] J. M. Holzbeierlein, P. C. Sogani, and J. Sheinfeld, "Histology and clinical outcomes in patients with bilateral testicular germ cell tumors: the Memorial Sloan Kettering Cancer Center experience 1950 to 2001," Journal of Urology, vol. 169, no. 6, pp. 2122-2125, 2003.

[11] C. Theodore, M. J. Terrier-Lacombe, A. Laplanche et al., "Bilateral germ-cell tumours: 22-Year experience at the Institut Gustave Roussy," British Journal of Cancer, vol. 90, no. 1, pp. 55$59,2004$.

[12] M. Hentrich, N. Weber, T. Bergsdorf, B. Liedl, R. Hartenstein, and A. Gerl, "Management and outcome of bilateral testicular germ cell tumors: twenty-five year experience in Munich," Acta Oncologica, vol. 44, no. 6, pp. 529-536, 2005.

[13] K. P. Dieckmann and U. Pichlmeier, "Clinical epidemiology of testicular germ cell tumors," World Journal of Urology, vol. 22, no. 1, pp. 2-14, 2004.

[14] K. P. Dieckmann, V. Loy, and P. Bttner, "Prevalence of bilateral testicular germ cell tumours and early detection based on contralateral testicular intra-epithelial neoplasia," British Journal of Urology, vol. 71, no. 3, pp. 340-345, 1993.

[15] S. D. Fosså, J. Chen, S. J. Schonfeld et al., "Risk of contralateral testicular cancer: a population-based study of 29515 U.S. Men," Journal of the National Cancer Institute, vol. 97, no. 14, pp. 10561066, 2005.

[16] D. R. Feldman, "The approach to the patient with synchronous bilateral germ cell tumors: a lesson in oncologic prioritization," Oncology, vol. 24, no. 8, pp. 761-763, 2010.

[17] S. Giacchetti, Y. Raoul, P. Wibault, J. P. Droz, B. Court, and F. Eschwege, "Treatment of stage I testis seminoma by radiotherapy: long-term results-a 30-year experience," International Journal of Radiation Oncology Biology Physics, vol. 27, no. 1, pp. 3-9, 1993.

[18] P. Kellokumpu-Lehtinen and A. Halme, "Results of treatment in irradiated testicular seminoma patients," Radiotherapy and Oncology, vol. 18, no. 1, pp. 1-7, 1990.

[19] W. G. Jones, S. D. Fossa, G. M. Mead et al., "Randomized trial of 30 versus $20 \mathrm{~Gy}$ in the adjuvant treatment of stage I testicular seminoma: a report on Medical Research Council Trial TE18, European Organisation for the Research and Treatment of Cancer Trial 30942 (ISRCTN18525328)," Journal of Clinical Oncology, vol. 23, no. 6, pp. 1200-1208, 2005.

[20] S. D. Fosså, A. Horwich, J. M. Russell et al., "Optimal planning target volume for stage I testicular seminoma: a medical research council randomized trial," Journal of Clinical Oncology, vol. 17, no. 4, pp. 1146-1154, 1999. 
[21] R. T. D. Oliver, G. M. Mead, G. J. S. Rustin et al., "Randomized trial of carboplatin versus radiotherapy for stage I seminoma: mature results on relapse and contralateral testis cancer rates in MRC TE19/EORTC 30982 study (ISRCTN27163214)," Journal of Clinical Oncology, vol. 29, no. 8, pp. 957-962, 2011.

[22] National Comprehensive Cancer Network, "NCCN Clinical Practice Guidelines in Oncology. Testicular Cancer. Version 1," 2012, http://www.nccn.org/professionals/physician_gls/pdf/ testicular.pdf.

[23] M. Soper, J. Hastings, H. Cosmatos, J. Slezak, R. Wang, and K. Lodin, "Observation versus adjuvant radiation or chemotherapy in the management of stage I seminoma: clinical outcomes and prognostic factors for relapse in a large US cohort," American Journal of Clinical Oncology, 2012.

[24] J. Aparicio, P. Maroto, X. del Muro et al., "Risk-adapted treatment in clinical stage I testicular seminoma: the third spanish germ cell cancer group study," Journal of Clinical Oncology, vol. 29, no. 35, pp. 4677-4681, 2011.

[25] A. Heidenreich, L. Weißbach, W. Höltl, P. Albers, S. Kliesch, and K. U. Köhrmann, "Organ sparing surgery for malignant germ cell tumor of the testis," Journal of Urology, vol. 166, no. 6, pp. 2161-2165, 2001.

[26] H. Steiner, L. Höltl, C. Maneschg et al., "Frozen section analysisguided organ-sparing approach in testicular tumors: technique, feasibility, and long-term results," Urology, vol. 62, no. 3, pp. 508-513, 2003.

[27] L. Weissbach, "Organ preserving surgery of malignant germ cell tumors," Journal of Urology, vol. 153, no. 1, pp. 90-93, 1995.

[28] O. Yossepowitch and J. Baniel, "Role of organ-sparing surgery in germ cell tumors of the testis," Urology, vol. 63, no. 3, pp. 421427, 2004.

[29] E. Tomita, T. Kondo, H. Nakazawa, F. Ito, Y. Hashimoto, and K. Tanabe, "Successful testis preservation for bilateral testicular tumors with a new chemotherapy-based protocol: initial results of three cases," International Journal of Urology, vol. 14, no. 9, pp. 879-882, 2007. 


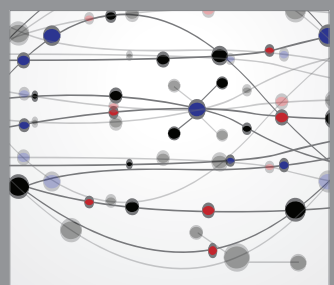

The Scientific World Journal
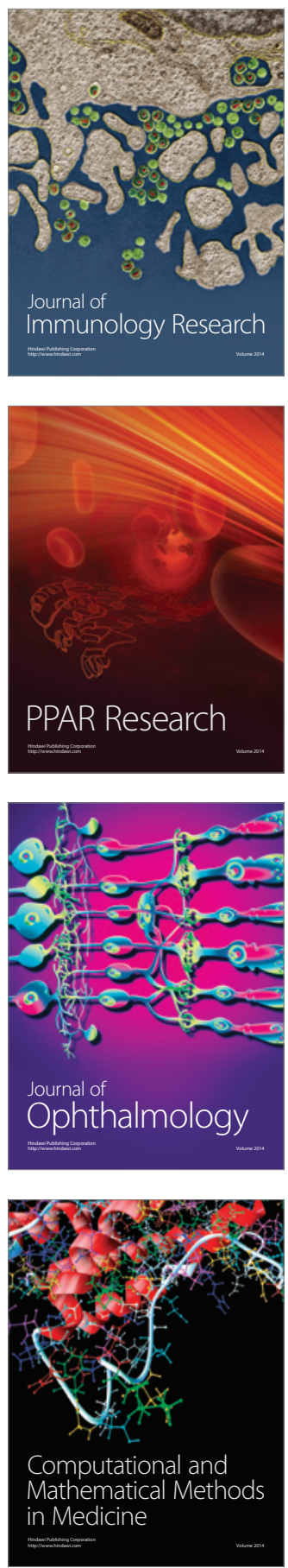

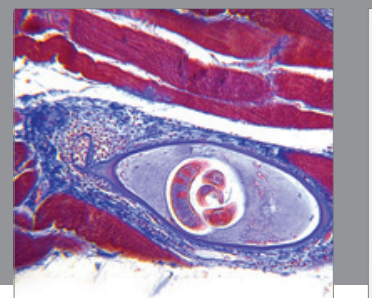

Gastroenterology

Research and Practice
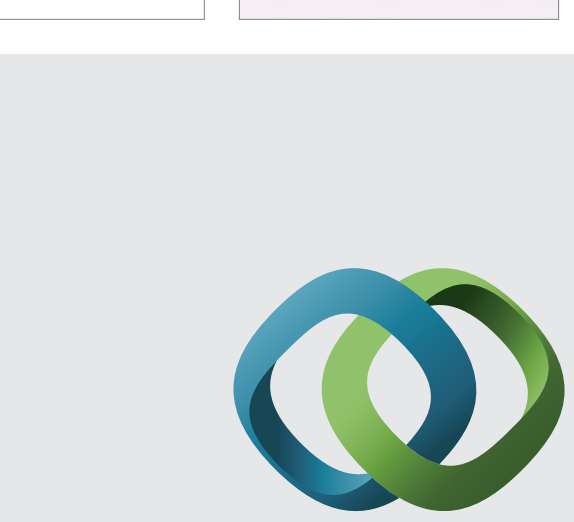

\section{Hindawi}

Submit your manuscripts at

http://www.hindawi.com
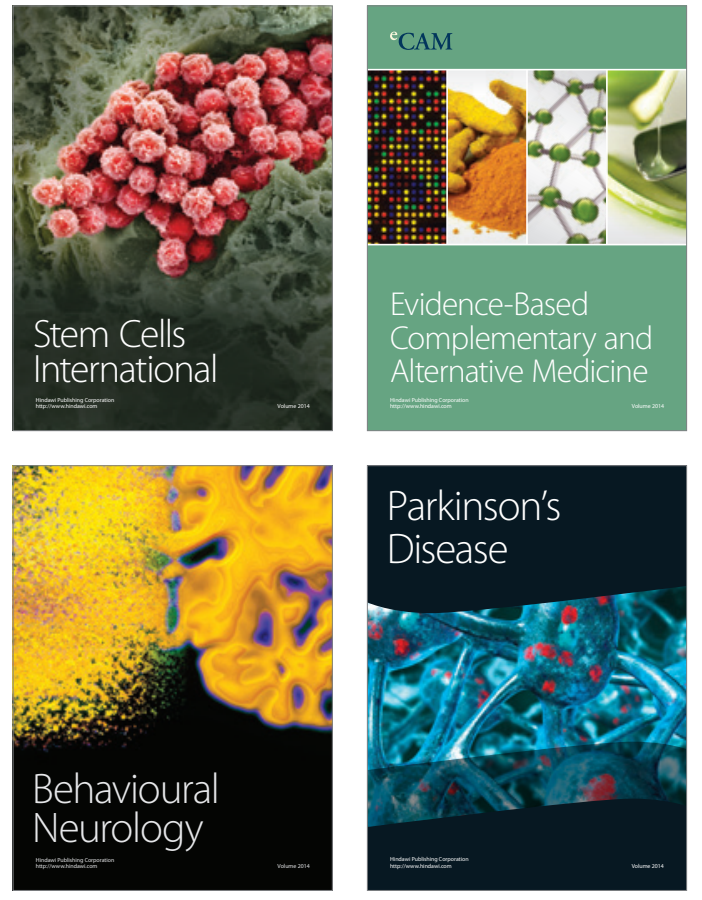
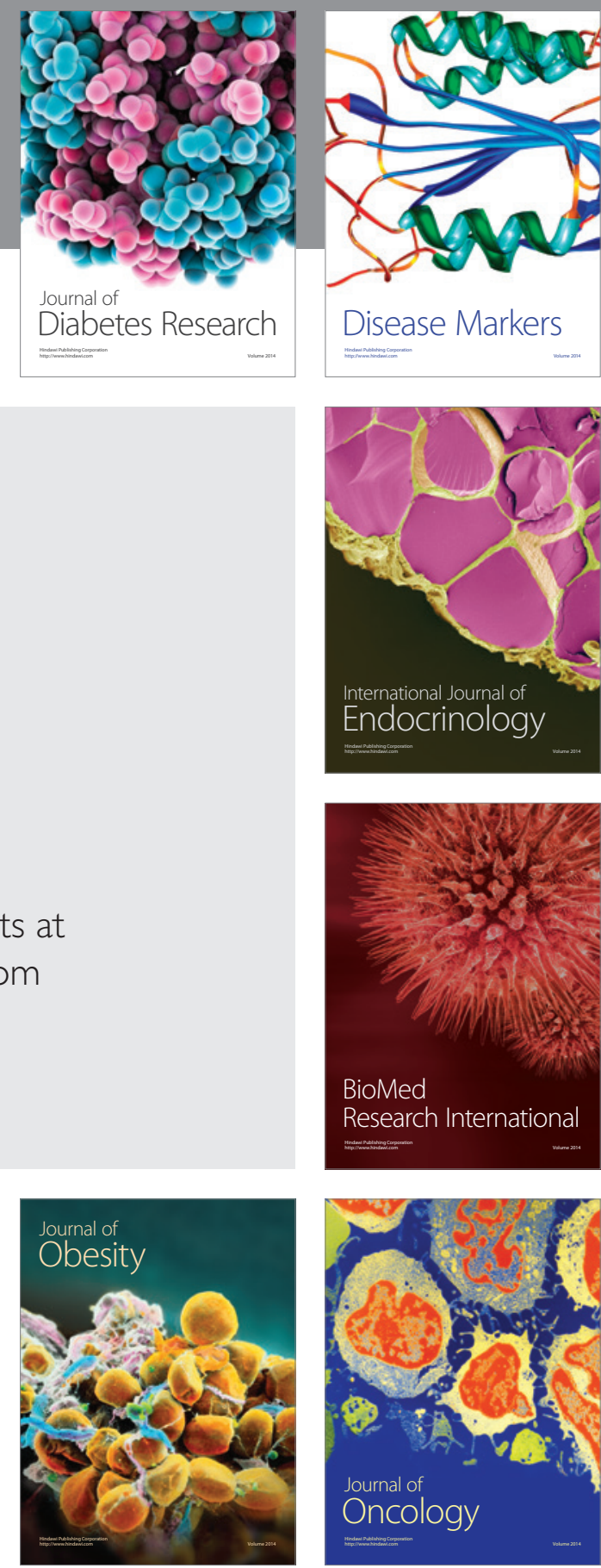

Disease Markers
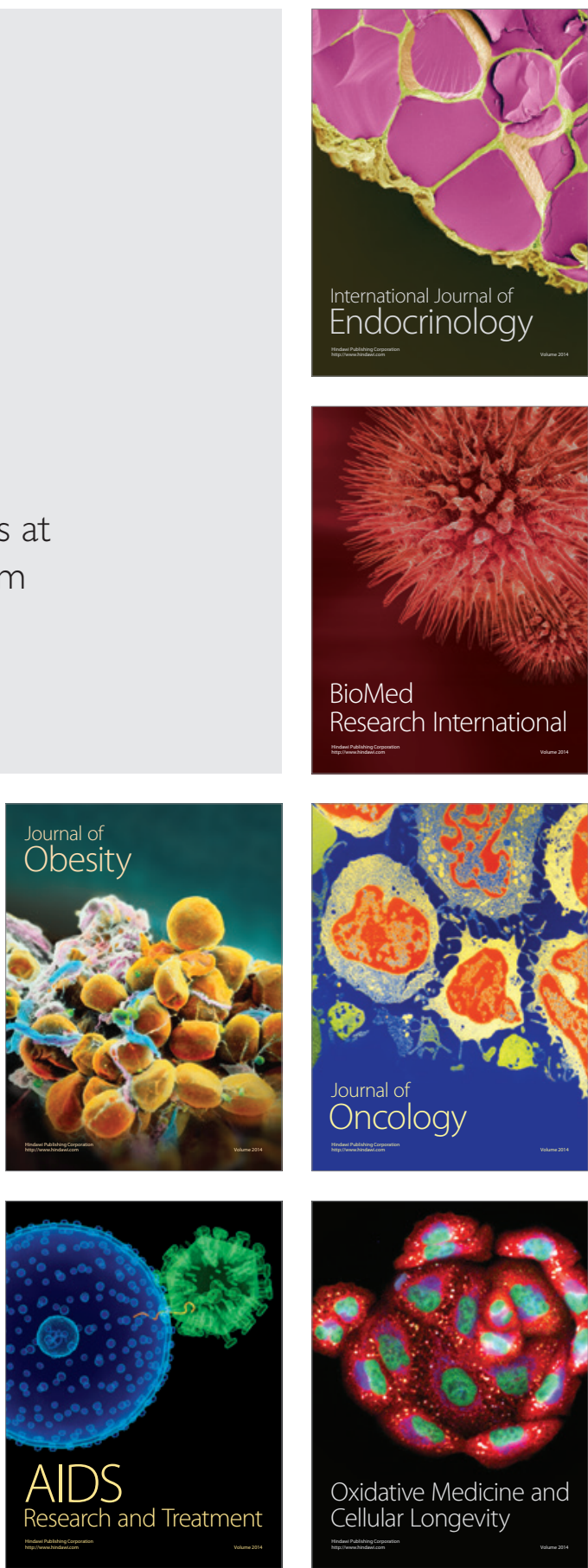